\title{
Contrasting responses of lizard occurrences to burrowing by a critically endangered seabird
}

\author{
J. H. Fischer ${ }^{1,4}$, C. F. McCauley ${ }^{1}$, D. P. Armstrong ${ }^{2}$, I. Debski ${ }^{3}$ and H. U. Wittmer ${ }^{1}$ \\ ${ }^{1}$ School of Biological Sciences, Victoria University of Wellington, PO Box 600, Wellington 6140, New Zealand \\ ${ }^{2}$ Wildlife Ecology Group, Massey University, Private Bag 11222, Palmerston North, New Zealand \\ ${ }^{3}$ Aquatic Unit, Department of Conservation, PO Box 10420, Wellington, New Zealand \\ ${ }^{4}$ Corresponding author. Address: School of Biological Sciences, Victoria University of Wellington, PO Box 600, \\ Wellington 6140, New Zealand. Email: johannesfischer@live.nl.ORCID: 0000-0003-3527-1671
}

Keywords: Diving Petrel, Interspecific interactions, Occupancy modelling, Oligosoma, Pelecanoides whenuahouensis, Skink.

\begin{abstract}
Seabirds are considered ecosystem engineers, because they facilitate ecosystem functioning (e.g., nutrient cycling), crucial for other marine and terrestrial species, including reptiles. However, studies of seabird-reptile interactions are limited. Here, we assessed the influence of the 'Critically Endangered' Whenua Hou Diving Petrel (Pelecanoides whenuahouensis) on the occurrence of two threatened skinks, Stewart Island green skink (Oligosoma aff. chloronoton) and southern grass skink $(O$. aff. polychroma). We surveyed skinks for 26 consecutive days at 51 sites with and 48 sites without Diving Petrel burrows in the dunes on Codfish Island (Whenua Hou), New Zealand. We used occupancy modelling to assess the influence of burrows on the occurrence of skinks, while accounting for other factors affecting occupancy $(\Psi)$ and detection probabilities $(p)$. Diving Petrel burrows had a contrasting effect on the occurrence of skinks. On average, $\hat{\Psi}$ of Stewart Island green skinks was $114 \%$ higher at sites with burrows compared to sites without, while $\hat{\Psi}$ of southern grass skinks was only $2 \%$ higher. Occurrence of both skinks was negatively influenced by the presence of the other skink species. On average $\hat{p}$ were low: 0.013 and 0.038 for Stewart Island green and southern grass skinks, respectively. Stewart Island green skinks appear attracted to burrows, which might facilitate thermoregulation (i.e., shelter from temperature extremes). The larger Stewart Island green skinks may subsequently exclude the smaller southern grass skinks at burrows, causing the contrasting relationships. We suggest that these interspecific interactions should be considered when implementing conservation management, e.g., through the order of species reintroductions.
\end{abstract}

Abbreviations: AIC - Akaike Information Criterion, GPS - Global Positioning System, IUCN - International Union for the Conservation of Nature, RVI - Relative Variable Importance.

Nomenclature: Fischer et al. (2018b), Hitchmough et al. (2016) and de Lange et al. (2013).

\section{Introduction}

Seabirds are considered ecosystem engineers as they have disproportionate impacts on their surrounding environments by providing various biophysical and biochemical ecosystem services (Taylor 2000a,b, Şekercioğlu et al. 2004, Şekercioğlu 2006). For example, seabirds facilitate nutrient cycling between marine and terrestrial ecosystems through the deposition of their faeces (guano), regurgitated prey items, feathers, and deceased eggs, chicks, and adults at their breeding colonies (Fukami et al. 2006, Otero et al. 2018). These deposits can even result in the creation of soil (Heine and Speir 1989). In addition, the nutrients deposited at the terrestrial colonies slowly return to the marine ecosystems, increasing productivity in (coastal) marine environments (Lorrain et al. 2017, Graham et al. 2018). Through the increased nutrient deposition, seabirds also change the terrestrial soil $\mathrm{pH}$ (Mulder and Keall 2001, Ellis 2005). Furthermore, the presence of seabirds facilitates terrestrial litter decomposition as well as marine bioerosion rates (Towns et al. 2009, Wardle et al. 2009,
Graham et al. 2018). Moreover, many seabirds, small $(<1$ $\mathrm{kg}$ ) Procellariiformes in particular, dig and breed in burrows, facilitating terrestrial bioturbation (i.e., natural soil displacement by burrowing organisms; Buxton et al. 2016, Orwin et al. 2016).

The biophysical and biochemical ecosystem services provided by seabirds have positive effects on unrelated plants and animals in both terrestrial and marine environments. For example, seabirds indirectly increase the productivity and seed germination of plants at their terrestrial colonies (Bandcroft et al. 2005). In addition, seabirds actively change the vegetation community through trampling and the collection of nesting material (Bancroft et al. 2005, Ellis 2005, Lameris et al. 2016). Seabirds also facilitate seed dispersal, which can result in remarkable trans-oceanic plant colonisations (Ellis 2005, Cheke and Hume 2008). Furthermore, seabirds indirectly change the composition and boost the diversity and abundance of terrestrial invertebrates (e.g., terrestrial amphipods, spiders, and insects) at their colonies (Markwell and Daugherty 2002, Towns et al. 2009, Wardle et al. 2009, 
Orwin et al. 2016). In the marine environments near seabird colonies, the presence of seabirds has an indirect and positive effect on other species groups. For example, seabird presence is correlated with increases in overall reef fish biomass and reef fish growth rates (Graham et al. 2018).

Seabirds also have a positive influence on reptiles (Markwell and Daugherty 2002, Corkery et al. 2015). Seabirdreptile relationships, however, appear poorly studied, because most investigations into these relationships remain anecdotal (e.g., Walls 1978). As an exception, the large and enigmatic tuatara (Sphenodon punctatus) has been shown to benefit from co-habiting fairy prion (Pachyptila turtur) burrows. Tuatara benefitted from warmer internal temperatures when inhabiting prion burrows and fed on prion chicks (Corkery et al. 2014, 2015). In addition, lizard communities (Scincidae and Diplodactylidae) were found to be more abundant and diverse on islands inhabited by seabirds than seabird-free islands (Markwell and Daugherty 2002). However, in the latter study, potential biases created by imperfect detections of these small lizards were not accounted for. Accounting for detection probabilities (e.g., through repeat surveys combined with occupancy modelling) is crucial, as non-detection does not indicate that a species is absent (MacKenzie et al. 2002, 2003, 2018).

Seabirds and lizards make up a substantial proportion of the native vertebrate fauna in New Zealand, but both species groups have suffered major population declines following the introduction of invasive mammalian predators (Taylor 2000a,b, Trewick and Gibb 2010, Hitchmough et al. 2016, Jewell 2017). The recently described Whenua Hou Diving Petrel (Pelecanoides whenuahouensis) is one of the most endangered species in the world. Only one Whenua Hou Diving Petrel colony on Codfish Island (Whenua Hou) survived historic extirpations throughout southern New Zealand caused by invasive predators (Taylor 2000b, Holdaway et al. 2003, Wood and Briden 2008, Wood 2016, Fischer et al. 2017b, $2018 b, c)$. Furthermore, storms and storm surges threaten the remaining breeding habitat of this species (i.e., fragile foredunes; Cole 2004, Fischer et al. 2018b,c). Consequently, the Whenua Hou Diving Petrel is listed as "Nationally Critical" in New Zealand (Robertson et al. 2017) and warrants listing as 'Critically Endangered' on the IUCN red list (Fischer et al. 2018b). Two threatened species of skink also occur within the dune in which the Whenua Hou Diving Petrel breeds: Stewart Island green skink (Oligosoma aff. chloronoton) and southern grass skink (O. aff. polychroma Clade 5). Both are listed as listed as "At Risk - Declining" in New Zealand following considerable range reductions caused by predation by invasive predators and habitat destruction (Hitchmough et al. 2016, Jewell 2017). Based on the studies conducted on tuatara (Corkery et al. 2014, 2015), we hypothesised that the two threatened small lizard species in the dune of Codfish Island would occur more frequently at sites with Whenua Hou Diving Petrel burrows than at sites without. To test our hypothesis, we used a large number of repeat surveys and occupancy modelling to account for imperfect detection of both skink species.

\section{Materials and methods}

\section{Study area}

Our study was conducted in the dunes of Sealers Bay $\left(46.766^{\circ} \mathrm{S}, 167.645^{\circ} \mathrm{E}\right)$ on Codfish Island (Whenua Hou), located approximately $3 \mathrm{~km}$ west of Stewart Island (Rakiura), New Zealand (Fig. 1). We defined our exact study area (approximately $0.065 \mathrm{~km}^{2}$ ) as following: the Sealers Bay beach (north), the coastal shrub, as defined by Wickes and Rance (2010) (east and south), and an unnamed stream (west). Our study area encompassed the entire Whenua Hou Diving Petrel colony (approximately 100 burrows). A small number (10-20 burrows) of Common Diving Petrels (Pelecanoides urinatrix) also nests within the Whenua Hou Diving Petrel colony (Cole, 2004, Trainor 2008, 2009). Both Stewart Island green skinks and southern grass skinks are common within our study area, but very little is known about their biology, including whether or not they are territorial (Jewell 2017). The southern skink (O. notosaurus) also occurs on Codfish Island (Jewell 2017) but appears absent within the confines of our study area (i.e., the foredunes). The vegetation community within the area is relatively uniform and dominated by native grasses, such as pingao (Ficinia spiralis), sand tussock (Poa billardierei), and club rush (Ficinia nodosa), invasive grasses, such as Yorkshire fog (Holcus lanatus) and Cocksfoot (Dactylis glomerata), and bidibids (Aceana novezealandia) (Wickes and Rance 2010). However, the vegetation cover within the study area varies considerably.

\section{Skink counts}

We surveyed the presence of skinks at sites with and without Diving Petrel burrows. To select sites with Diving Petrel burrows, we searched the entire study area for burrows by walking back and forth in pairs (Fischer et al. 2018c) in September-October 2017. We found a total of 120 Diving Petrel burrows and included all these sites in our skink surveys. All 120 burrows were active in the 2017 season (assessed using stick palisades; Cole 2004). Inactive burrows close relatively quickly due to dynamic nature of the dune. To select the sites without Diving petrel burrows, we created 59 random points within our study area using ArcGIS 10 and located them within the study area using a handheld GPS. We then physically marked sites with and without Diving Petrel sites in situ, using fibre glass poles and track markers to ensure skinks were surveyed at the exact same site on every occasion.

We surveyed skinks at all sites with $(n=120)$ and without Diving Petrel burrows $(n=59)$ from mid-November to midDecember 2017 (26 repeat surveys). We considered a circle with an area of $1 \mathrm{~m}^{2}$ (radius $=56 \mathrm{~cm}$ ) around each marker pole as the survey site. We alternated surveys between observers (JHF and CFM) and visited sites in a pre-defined order to minimise disturbance, but rotated start and end points (i.e., from northeast to southwest or vice versa; Fig. 1). We conducted skink surveys any time between 07:30 and 19:30. We recorded skink sightings as Stewart Island green skink, 


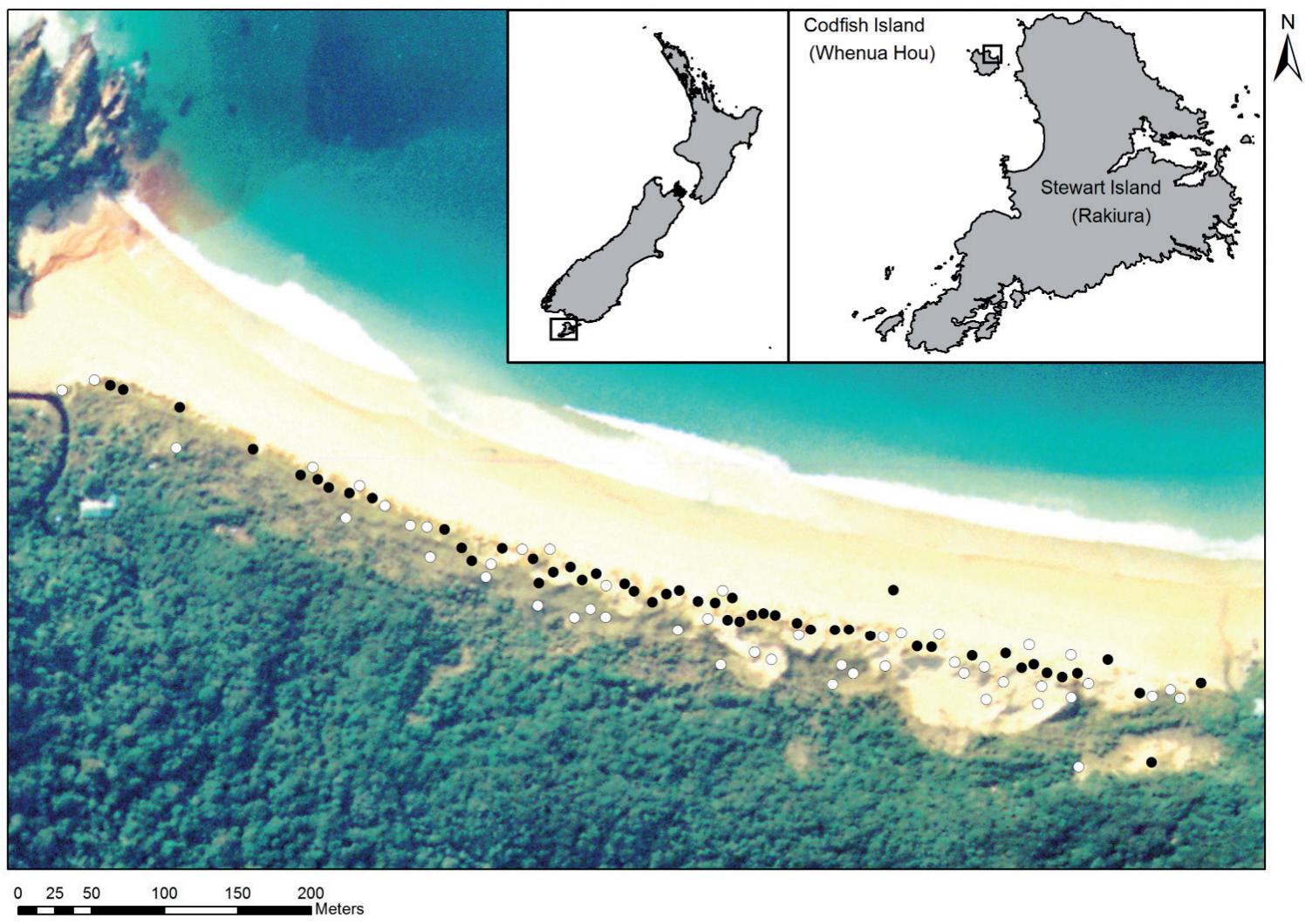

Figure 1. Skink survey sites $(n=99)$ in the Sealers Bay dunes, Codfish Island (Whenua Hou). Sites with Diving Petrel burrows $(n=51)$ are represented with black circles and sites without burrows $(n=48)$ are represented with white circles.

southern grass skink, or unidentified skink per site per count. Skink identification was based on differences in size (snoutvent-length of Stewart Island green skinks $\leq 125 \mathrm{~mm}$, compared to $\leq 80 \mathrm{~mm}$ for southern grass skinks) and body coloration (Jewell 2017).

We ensured independence of our survey sites (i.e., the same individual skink cannot be detected at multiple sites) through retrospective subsampling, as Diving Petrels can breed in extreme proximity of each other (i.e., up to 6 burrows $/ \mathrm{m}^{2}$; Taylor 2000b). For our subsampling, we used data from a closely-related skink species (Herbert and Bell 2012). Most (80\%) of northern spotted skinks (O. kokowai) did not travel further than $4 \mathrm{~m}$ over an eight-month study period (Phillpot 2000, Melzer et al. 2017). We doubled this travelling distance to get a minimum-distance constraint of $8 \mathrm{~m}$ (measured from the centre of each site). We then ran 1000 iterations of a random subsampling approach. Specifically, we randomly selected the first site to which we applied our minimum-distance constraint. After 1000 iterations, we selected the subsample with the highest number of remaining sites. After distance-constrained random subsampling, 99 survey sites remained, consisting of 51 sites with burrows and 48 sites without (Fig. 1).

We assumed that our ability to identify skinks was equal for both species. We therefore used the naïve occupancy (i.e., number of sites with detected skinks divided by the total number of survey sites) of each species to inform a weighted random allocation to assign unidentified skinks to either of the two species. The naïve occupancy was 0.091 and 0.161 for Stewart Island green skinks and southern grass skinks, respectively. This ratio informed the weighted random allocation of the unidentified skinks $(n=9)$ as follows: $P=0.36$ for Stewart Island green skinks, $P=0.64$ for southern grass skinks. Ultimately, our approach of random subsampling and random allocation of unidentified skinks resulted in detection histories for each skink species per independent survey site, consisting of $1 \mathrm{~s}$ (seen) and $0 \mathrm{~s}$ (not seen), as required for occupancy modelling (MacKenzie et al. 2002, 2003).

\section{Occupancy modelling}

We fitted single-species, single-season occupancy models to our detection histories of both skink species to assess the influence of Diving Petrel burrows on the occurrence of skinks, while accounting for imperfect detection (MacKenzie et al. 2002, 2003, 2018). We included the effects of potentially important covariates on both occupancy $(\Psi)$ and detection probabilities $(p)$ in our models. Specifically, we hypothesized that $\Psi$ could be affected by the presence of Diving Petrel burrows (Walls 1978, Markwell and Daugherty 2002, Corkery et al. 2014, 2015), the presence of the other skink species (Petren and Case 1998), the vegetation cover (Berry et al. 2005, Seddon et al. 2011), and/or the distance to sea (Fischer et al. 2018c). Consequently, we modelled the influence of 1) the presence of a Diving Petrel burrow (binomial; denoted as 
burrow), 2) the presence of the other skink species (i.e., naive occupancy; binomial; denoted as $s g s$ or sigs for southern grass skinks and Stewart Island green skinks, respectively), $3)$ the vegetation cover $\left(\mathrm{m}^{2}\right.$; modelled as a quadratic function when a concave relationship was detected, or as a linear function when a convex relationship was detected; denoted as $v^{2} g^{2}$ or veg, respectively), and 4) the distance to sea (m from the spring-tide line; denoted as sea) on the of both skink species. Additionally, we hypothesized that our ability to detect skinks could be affected by the vegetation cover (Roughton 2005) and/or the time of day (Armstrong 2016). Consequently, we modelled the influence of 1) the vegetation cover $\left(\mathrm{m}^{2}\right.$ and modelled as a linear function; denoted as veg) and 2) the timing of each survey (hours after sunrise; denoted as $t$ ) on the $p$ of both skink species. We z-transformed all continuous variables $\left(\mathrm{veg}^{2}\right.$, veg, sea, and $t$ ) prior to the occupancy modelling (MacKenzie et al. 2018).

We used a model-averaging approach informed by the Akaike Information Criterion (AIC; Burnham and Anderson 2002) to identify the relative importance of covariates affecting $\Psi$ and $p$ for Stewart Island green skinks and southern grass skinks. We compared models with all combinations of covariates affecting $\Psi$ while retaining $p$ fully parameterized. We included null models, denoted as $(\cdot)$, but excluded interactions. We only included covariates in the same model with a Spearman's correlation coefficient of $r \leq 0.6$. For each model, we generated the $-2 * \log$ likelihood $(-2 L)$, the logittransformed estimate of the intercepts $(\hat{\alpha}) \pm$ standard error (SE), the logit-transformed estimate of the slope per covariate $(\hat{\beta}) \pm \mathrm{SE}$, and the variance-covariance matrix (Burnham and Anderson 2002, MacKenzie et al. 2018). We summed the AIC weights $(w)$ from the models to quantify the relative variable importance (RVI) per covariate. We then used model averaging to obtain a model-averaged $\hat{\beta} \pm \mathrm{SE}$ per covariate. We applied the Delta method (Seber 1982; MacKenzie et al. 2018) to obtain $\hat{\Psi} \pm$ SEs at sites with and without Diving Petrel burrows and $\hat{p} \pm$ SEs per model. When applying the Delta method for $\hat{\Psi}$, we used the mean value for veg (and $v e g^{2}$ ) and sea and used 0 (i.e., absence) for sgs or sigs in models that contained these covariates. When applying the Delta method for $\hat{p}$, we used the mean values of veg and $t$ (i.e., between 13:00 and 14:00). Finally, we used model-averaging to obtain model-averaged $\hat{\Psi} \pm$ SEs for sites with and without burrows and model-averaged $\hat{p} \pm$ SEs per species.

Statistical analyses were conducted in Program R 3.3.1 ( $\mathrm{R}$ core development team 2016) and PRESENCE 2.12.15 (Hines 2018), while data visualisations were created in Program R 3.3.1, using the package ggplot2 (Wickham 2009) and qgraph (Epskamp et al. 2017).

\section{Results}

Naïve occupancy at sites with burrows was $0.118(6 / 51)$ for Stewart Island green skinks and $0.216(11 / 51)$ for southern grass skinks (following random allocation of unidentified skinks). Naïve occupancy at sites without burrows was 0.083 (4/48) for Stewart Island green skinks and 0.188 (9/48) for southern grass skinks. Spearman's correlation tests indicated
Table 1. Spearman correlation coefficients $(r)$ between covariates included in occupancy models. Covariates included the presence of Stewart Island green skinks (sigs), the presence of southern grass skinks ( $\mathrm{sgs}$ ), vegetation cover (veg), presence of a Diving Petrel burrow (burrow), and distance to sea (sea).

\begin{tabular}{lrrrr}
\hline & sigs & sgs & veg & burrow \\
\cline { 5 - 6 } sigs & & & & \\
sgs & -0.085 & & & \\
veg & 0.369 & 0.216 & & \\
burrow & 0.057 & 0.035 & -0.073 & \\
sea & 0.106 & 0.090 & 0.431 & -0.391 \\
\hline
\end{tabular}

that no covariates were highly correlated ( $r \geq 0.6$; Table 1). Summaries of occupancy models for Stewart Island green skinks and southern grass skinks can be found in the Table 2 and 3, respectively. A comparison between the $\triangle \mathrm{AIC}$ and $-2 L$ did not indicate the presence of any pretender variables (Anderson 2008). Stewart Island green skink occupancy was positively influenced by the presence of Diving Petrel burrows $\left(\mathrm{RVI}=0.675\right.$; model-averaged $\widetilde{\beta_{\text {burrow }}}=2.107 \pm 1.370$ ). Southern grass skink occupancy also showed a positive (but considerably weaker) relationship with Diving Petrel burrows $\left(\mathrm{RVI}=0.278\right.$; model-averaged $\widehat{\beta_{\text {burrow }}}=0.093 \pm 0.684$ ) (Fig. 2). The model-averaged $\hat{\Psi}$ at for Stewart Island green skinks was $0.328(\mathrm{SE}=0.172-0.489)$ for sites with burrows and 0.153 ( $\mathrm{SE}=0.092-0.261$ ) for sites without (Fig. 3). The model-averaged $\hat{\Psi}$ for southern grass skinks was 0.318 $(\mathrm{SE}=0.235-0.415)$ for sites with burrows and 0.312 (SE $=0.230-0.409$ ) for sites without (Fig. 3). Notably, $5.6 \%$ of the records of Stewart Island green skinks and $6.1 \%$ of the records of southern grass skinks were of communal basking (i.e., two skinks basking within $\leq 50 \mathrm{~cm}$ from each other; Fig. 4). Communal basking of both species was only observed at sites with Diving Petrel burrows.

Occurrence of Stewart Island green skinks was negatively influenced by the presence of southern grass skinks (RVI = 0.531 ; model-averaged $\left.\widehat{\beta_{s g s}}=-1.607 \pm 1.253\right)$. Vice versa, southern grass skink occurrence was negatively influenced by the presence of Stewart Island green skinks (RVI $=0.521$; model-averaged $\widetilde{\beta_{\text {sigs }}}=-1.526 \pm 1.162$ ). Additionally, Stewart Island green skink occurrence was positively influenced by vegetation cover $\left(\mathrm{RVI}=0.487\right.$; model-averaged $\widetilde{\beta_{\text {veg }}}=3.107$ $\pm 1.744)$. Contrastingly, southern grass skink occurrence indicated an optimum vegetation cover $(\mathrm{RVI}=0.388$; modelaveraged $\overparen{\beta_{\text {veg }}}=2.482 \pm 1.892 ;$ model-averaged $\widetilde{\beta_{\text {veg }}{ }^{2}}=-1.653$ $\pm 1.691)$. Furthermore, Stewart Island green skink occurrence was slightly positively influenced by distance to sea (RVI = 0.263 ; model-averaged $\overparen{\beta_{\text {sea }}}=0.062 \pm 0.508$ ). Southern grass skink occurrence was slightly negatively influenced by the distance to sea $\left(\mathrm{RVI}=0.305 ;\right.$ model-averaged $\widetilde{\beta_{\text {sea }}}=-0.189$ $\pm 0.328)$.

Detection probabilities of both skink species were very low. Model-averaged $\hat{p}$ was $0.013(\mathrm{SE}=0.003-0.053)$ for Stewart Island green skinks and $0.038(\mathrm{SE}=0.028-0.051)$ for southern grass skinks. Detection of Stewart Island green skinks had a negative relationship with time of day (model- 


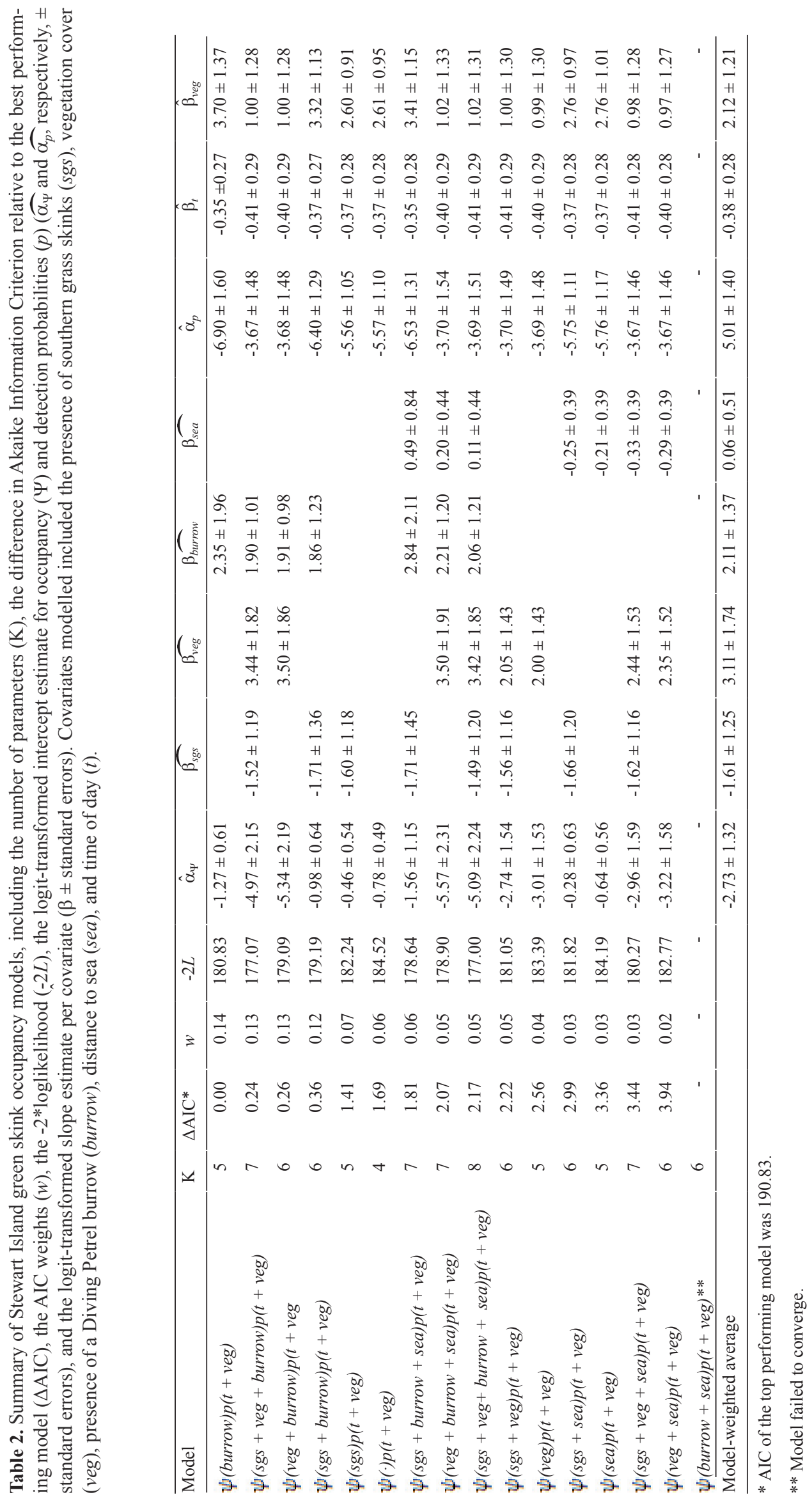




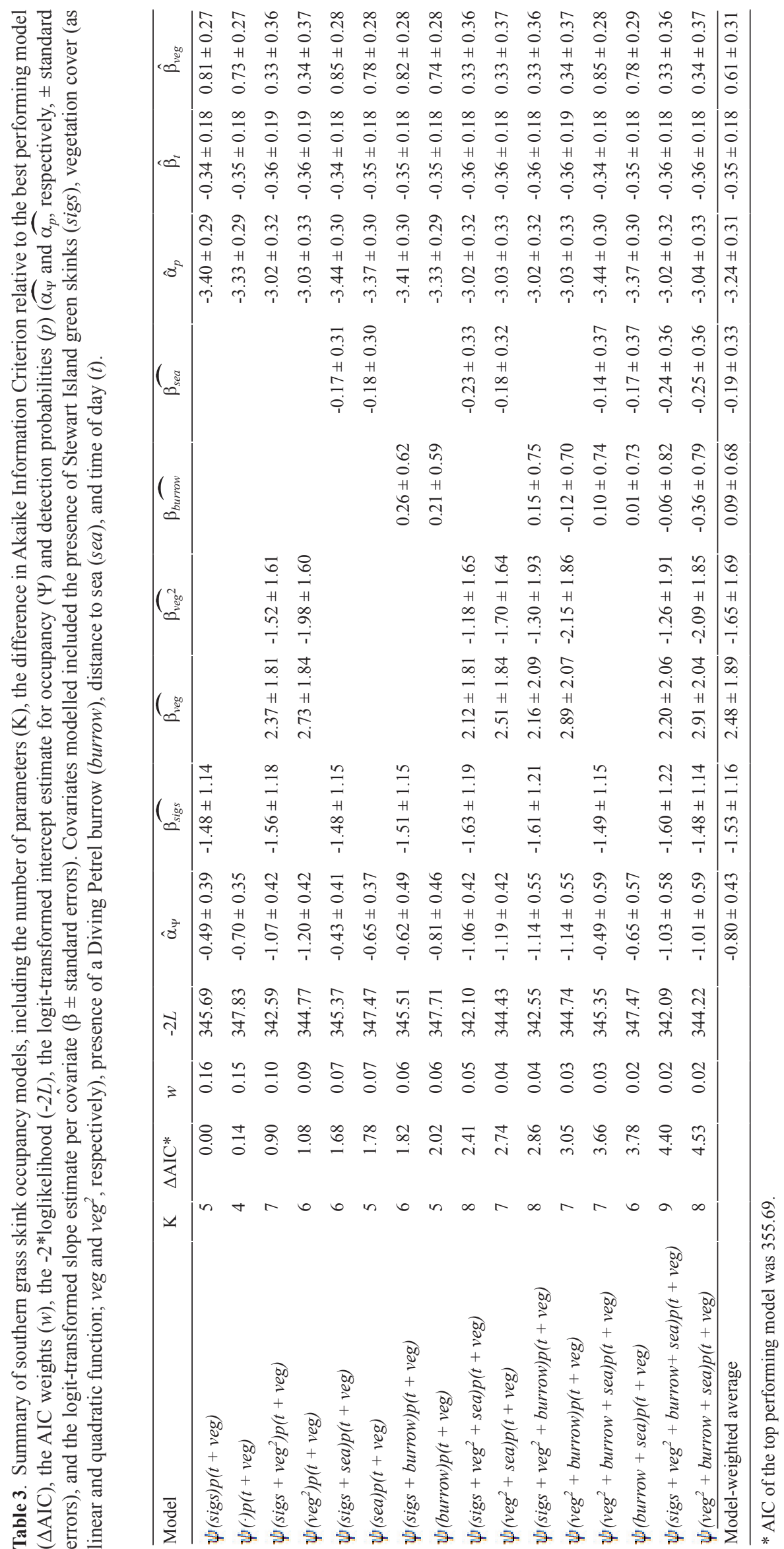


Figure 2. Relative variable importance (RVI; represented by arrow width and darkness) and model-averaged estimates of logit-transformed slopes $(\hat{\beta}) \pm$ standard errors of covariates influencing occupancy probability $(\Psi)$ in occupancy models for Stewart Island green skinks (left) and southern grass skinks (right).

Figure 3. Model-averaged estimates of occupancy probabilities $(\hat{\Psi})$ for Stewart Island green skinks (left) and southern grass skinks (right) at sites with (black circles) and without (white circles) Diving Petrel burrows, including standard errors.
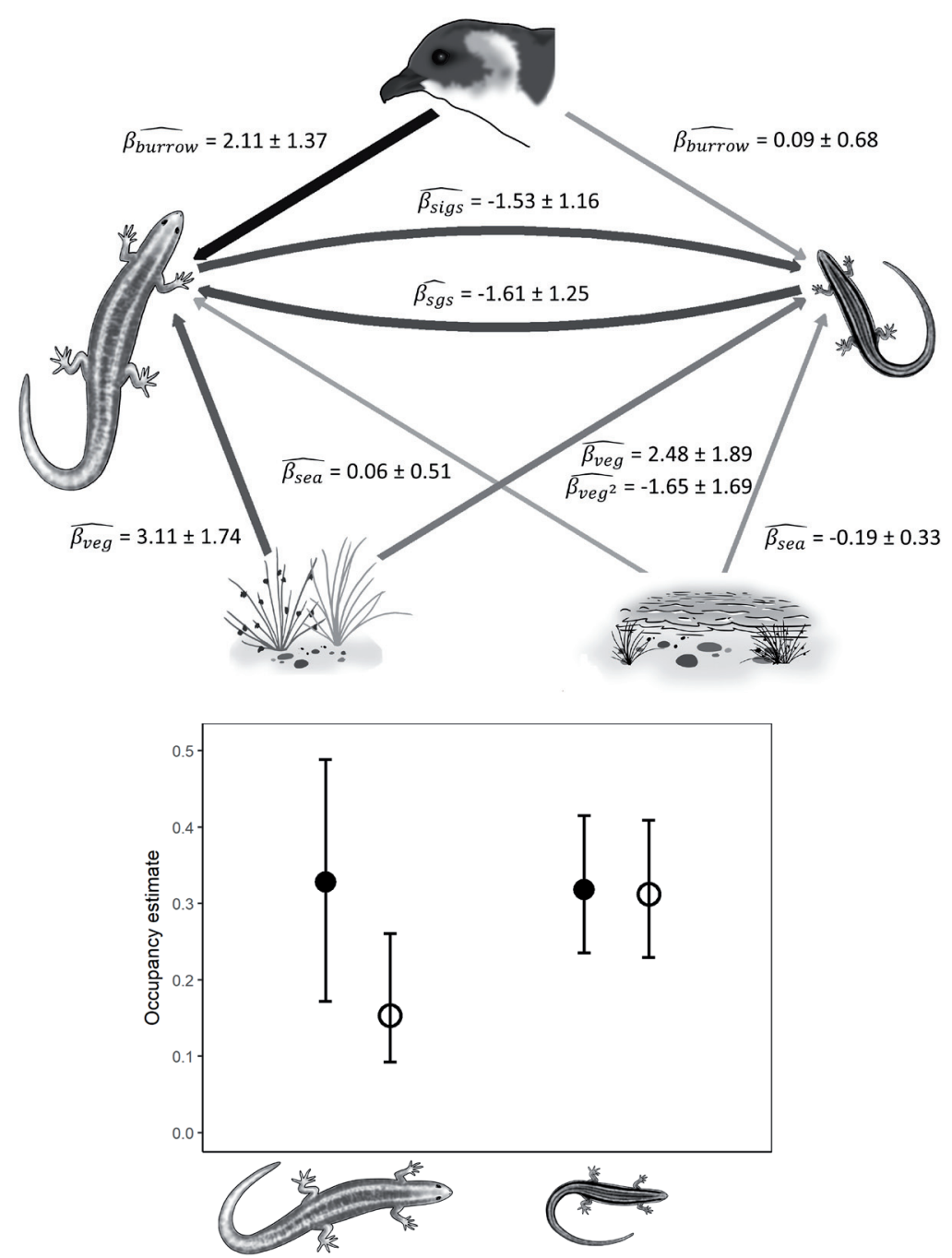

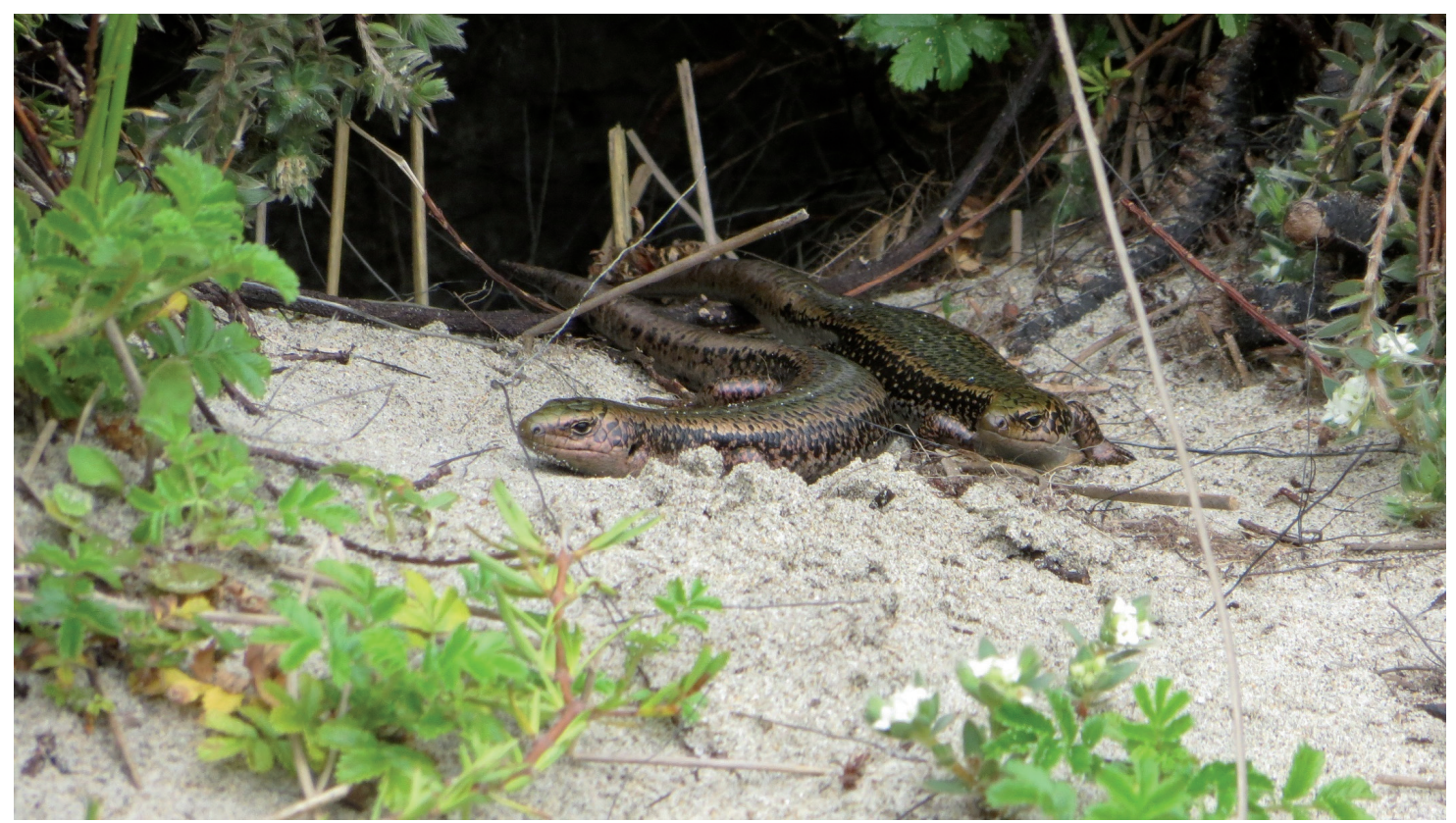

Figure 4. Communal basking of Stewart Island green skinks at a Whenua Hou Diving Petrel burrow. Photo credit: Johannes H. Fischer. 
averaged $\hat{\beta}_{t}=-0.382 \pm 0.282$ ), as did detection of southern grass skinks (model-averaged $\hat{\beta}_{t}=-0.352 \pm 0.182$ ). Counts earlier in the day were more likely to detect skinks. In addition, detection of Stewart Island green skinks had a positive relationship with vegetation cover (model-averaged $\widetilde{\beta_{\text {veg }}}$ $=2.123 \pm 1.210$ ). Detection of southern grass skinks was also positively influenced by vegetation cover (model-averaged $\widetilde{\beta_{\text {veg }}}=0.610 \pm 0.312$ ).

\section{Discussion}

Our results indicate that Diving Petrel burrows in sand dunes can have a positive effect on the occurrence of Stewart Island green skinks, and to a small extent, southern grass skinks. Despite not testing for the underlying mechanisms driving the elevated skink occurrence at Diving Petrel burrows, we hypothesise that the burrows offer refugia from heat stress. Previous research has consistently highlighted that lizard habitat selection is influenced by the need to avoid harsh and/or fluctuating environmental temperatures (Downes and Shine 1998, Milne et al. 2003, Du et al. 2006, Andersson et al. 2010, Jewell 2017). To thermoregulate, ectotherms such as lizards, can exhibit a behaviour known as 'shuttling', whereby they utilise thermal shelters periodically throughout the day to maintain stable internal temperatures (Milne et al. 2003, Andersson et al. 2010, Corkery et al. 2015, Jewell 2017). We thus suggest that Diving Petrel burrows facilitate 'shuttling' behaviour in Stewart Island green skinks (and to a certain extent, southern grass skinks), allowing them to shelter from the extreme temperature maxima that are common within dune systems (Fischer et al. 2018a).

Predation may be another possible driver of habitat selection in small lizards (Downes and Shine 1998). The dunes of Codfish Island currently harbour comparatively few diurnal skink predators since the eradication of all invasive predators: Weka (Gallirallus australis), Brush-tailed Possum (Trichosurus vulpecula), and Polynesian Rats (Rattus exulans; McClelland 2002, Middleton 2007). However, prior to human colonisation, New Zealand's avifauna was more diverse, and many bird species were flightless, terrestrial, and potentially predatory (Duncan and Blackburn 2004, Trewick and Gibb 2010, Wood et al. 2017). As such, the use of burrows by Stewart Island green skinks (and southern grass skinks) could also be explained by predator avoidance on an evolutionary time scale.

Our anecdotal records of communal basking of both skink species, limited to Diving Petrel burrows, suggest that these burrows may play a role in the skinks' social behaviours (Downes and Shine 1998). Communal basking is rarely documented in New Zealand skinks, and these are the first records of communal basking in both Stewart Island green skinks and southern grass skinks (Jewell 2017, S. Herbert in lit. 2018). These intraspecific interactions, however, need further investigations (e.g., into the sex and age of communally basking individuals). Alternatively, our records of communal basking in both species of skinks could be explained by coincidental and independent behaviour of individual skinks.
Stewart Island green skinks may exclude southern grass skinks from occupying sites with Diving Petrel burrows. Both skink species exhibited a negative relationship with the presence of the other skink species, indicating a level of interspecific competition or avoidance (Downes and Shine 1998, Petren and Case 1998). This result is likely due to autocorrelation (i.e., if one species is negatively correlated with the other, then the reverse will be also true). It is probable that the smaller species (southern grass skink) is avoiding the larger species (Stewart Island green skink), as larger skinks predate on smaller skinks, or consume their autotomized tails (Petren and Case 1998, S. Herbert in lit. 2018). As such, the larger Stewart Island green skinks are likely to exclude the smaller southern grass skinks from sites with Diving Petrel burrows, causing the observed difference in occurrence at Diving Petrel burrows. Perhaps, southern grass skinks show a strong relationship with Diving Petrel burrows in the absence of Stewart Island green skinks. We, however, cannot assess the relationship between these two skink species in further detail, because we used the naïve occupancy within single-species occupancy models (MacKenzie et al. 2002, 2018). Co-occurrence occupancy modelling would allow for detailed assessments of these interspecific relationships (MacKenzie et al. 2004, Richmont et al. 2010). However, our current approach suggests uncertainty (multiple models with $\Delta \mathrm{AIC}<2.00$ in both model sets). Therefore, it seems ill-advised to elevate the number of estimated parameters from two ( $\Psi$ and $p$ ) to eight $\left(\Psi^{A}, \Psi^{B \mid A}, \Psi^{B \mid a}, p^{A}{ }_{j}, p^{B}, r_{j}^{A}, r_{j}^{B \mid A}\right.$, and $r^{B \mid a}$ ), as would be required for co-occurrence occupancy models (Richmont et al. 2010, MacKenzie et al. 2018).

The low detection probabilities of both skink species in our study illustrate the importance of repeat surveys in combination with occupancy modelling when studying cryptic species (MacKenzie et al. 2002, 2003, 2018). The modelled detection probabilities showed a positive relationship with vegetation cover. This unexpected relationship can be explained by a negative relationship of flight-initiation-distance with vegetation cover (Capizzi et al. 2007). In other words, skinks are less likely to flee with more vegetation cover around them, and thus more likely to be detected. The negative relationship of detection probabilities with time of day can be explained by the need to bask and thermoregulate in the morning (Downes and Shine 1998, Du et al. 2006, Andersson et al. 2010). While we employed visual surveys, detection probabilities of skinks may be higher when other survey techniques were employed (e.g., pitfall traps; Herbert and Bell 2012). These techniques, however, have other drawbacks (e.g., trap-related mortalities; Enge 2001), which cannot be overcome with repeat surveys and occupancy modelling.

Seabirds like the Whenua Hou Diving Petrel would have facilitated shuttling behaviour, and potentially social behaviours, in skinks throughout New Zealand prior to the arrival of invasive predators. It is likely that the interspecific interactions between the Whenua Hou Diving Petrels, Stewart Island green skinks, and southern grass skinks were once widespread throughout the historical range of these three species, but disappeared following local extinctions of the Whenua Hou Diving Petrel (Taylor 2000b, Holdaway et al. 2003, Wood 
and Briden 2008, Wood 2016, Fischer et al. 2017b, Jewell 2017, Fischer et al. 2018b,c). For example, both skink species have relict populations on Stewart Island, while the Whenua Hou Diving Petrel is extirpated from its dune systems (Wood and Briden 2008, Wood 2016, Jewell 2017). Finally, similar interspecific interactions may have occurred between other, closely-related skink species (Oligosoma spp.) and the Whenua Hou Diving Petrel, outside the range of Stewart Island green skinks and southern grass skinks. Such interactions would have equally vanished with the local extinctions of the Whenua Hou Diving Petrels.

Interspecific interactions form crucial parts of ecosystems and conservation management should take such interactions into account (Şekercioğlu et al. 2004, Fischer et al. 2017c). Whenua Hou Diving Petrels are the only seabird species in New Zealand that breeds en masse in dune systems (Fischer et al. 2017a,b, 2018a,b,c). Aside from the likely biophysical and biochemical ecosystem services provided by Whenua Hou Diving Petrels across dune systems (e.g., nutrient cycling, bioturbation, seed dispersal; Ellis 2005, Orwin et al. 2016, Otero et al. 2018), Whenua Hou Diving Petrels may increase the habitat suitability for skinks (Milne et al. 2003, Corkery et al. 2015). Therefore, this 'Critically Endangered' species might be a crucial ecosystem engineer within its specific habitat type. All three species clearly merit targeted conservation management, which should take the interactions between these three species into account. One management option for skinks could be to follow Souter et al. (2004) and install Diving Petrel burrow replicas in areas where relict skink populations persist, but Whenua Hou Diving Petrels have been extirpated (e.g., Stewart Island; Jewell 2017). A more inclusive management strategy would be a reintroduction of the Whenua Hou Diving Petrel into a dune system within its natural range (Miskelly and Taylor 2004, Miskelly et al. 2009, Fischer et al. 2018b,c). Such a Whenua Hou Diving Petrel reintroduction would also benefit any relict skink population. Another option would be to follow a Whenua Hou Diving Petrel reintroduction, with reintroductions (or reinforcements; Seddon et al. 2014) of skinks. Such multi-stage, multi-species reintroductions may result in better reintroduction results and the reinstatement of interspecific interactions (Tylianakis et al. 2010, Seddon et al. 2014). Interspecific interactions are lost at higher rates than species, resulting in ecosystem degradation before the extinction of species (Valiente-Banuet et al. 2015). Therefore, reintroductions (and reinforcements) aimed at reinstating interspecific interactions (next to locally extirpated species) will improve overall ecosystem health and functioning.

Acknowledgements: Our study was generously supported by the National Geographic Society (WW-249C-17), Birds NZ (Birds NZ Research Fund 2017), and the Centre of Biodiversity and Restoration Ecology (Student Award 2017). JHF was supported by a Victoria University of Wellington Doctoral Scholarship, CFM was supported by a Victoria University of Wellington Summer Research Scholarship. Additionally, we are grateful to the Ngāi Tahu for granting access to Codfish Island. We also thank S. Bose (Fig. 1) and
D. Young (Figures 2 and 3) for the electronic artwork. Finally, we are indebted to V. Anton, S. Herbert, and one anonymous reviewer for improving previous versions of this manuscript.

\section{References}

Andersson, D. R. 2008. Model Based Inference in the Life Sciences: A Primer on Evidence. Springer, Berlin.

Andersson, M., A. Krockenberger and L. Schwarzkopf. 2010. Experimental manipulation reveals the importance of refuge habitat temperature selected by lizards. Austral Ecol. 35:294299.

Armstrong, D.P. 2016. Using reference sites to account for detection probability in occupancy surveys for freshwater turtles. Herpetol. Conserv. Biol. 11:505-518.

Bancroft, W.J., D.J. Roberts and M.J. Garkalis. 2005. Burrowing seabirds drive decreased diversity and structural complexity, and increased productivity in insular-vegetation communities. Aust. J. Bot. 53:231-241.

Berry, O., M.D. Tocher, D.M. Gleeson and S.D. Sarre. 2005. Effect of vegetation matrix on animal dispersal: genetic evidence from a study of endangered skinks. Conserv. Biol. 19:855-864.

Burnham, K.P. and D.A. Anderson. 2002. Model Selection and Multimodel Inference: A Practical Information-theoretic Approach. Springer, New York.

Buxton, R.T., C.J. Jones, P.O. Lyver, D.R. Towns and S.B. Borelle. 2016. Deciding when to lend a helping hand: a decision-making framework for seabird island restoration. Biodivers. Conserv. 25: 467-484.

Capizzi, D., L. Luiselli and L. Vignoli. 2007. Flight initiation distance in relation to substratum type, sex, reproductive status and tail condition in two lacertids with contrasting habitats. AmphibiaReptilia 28:403-407.

Cheke, A. and J.P. Hume. 2008. Lost Land of the Dodo: An Ecological History of Mauritius, Reunion \& Rodrigues. Bloomsbury Publishing, London.

Cole, R. 2004. Summary of South Georgian Diving Petrel field observations for 2003/04, Codfish Island/Whenua Hou. Department of Conservation, Invercargill.

Corkery, I., B. Bell and N. Nelson. 2014. Investigating kleptothermy: A Reptile-Seabird association with thermal benefits. Physiol. Biochem. Zool. 87:216-221.

Corkery, I., B.D. Bell and N.J. Nelson. 2015. Is the breeding behaviour of nesting seabirds influenced by the presence of a predatory reptile - the tuatara? J. Roy. Soc. New Zeal. 45:21-30.

de Lange, P.J., J.R. Rolfe, P.D. Champion, S.P. Courtney, P.B. Heenan, J.W. Barkla, E.K. Cameron, D.A. Norton and R.A. Hitchmough. 2013. Conservation status of New Zealand indigenous vascular plants, 2012. Department of Conservation, Wellington

Downes, S. and R. Shine. 1998. Heat, safety or solitude? Using habitat selection experiments to identify a lizard's priorities. Anim. Behav. 55:1387-1396

Du, W.G., L. Shou and J.Y. Shen. 2006. Habitat selection in two sympatric Chinese skinks, Eumeces elegans and Sphenomorphus indicus: do thermal preferences matter? Can. J. Zool. 84:13001306

Duncan, R.P. and T.M. Blackburn. 2004. Extinction and endemism in the New Zealand avifauna. Global. Ecol. Biogeogr. 13:509-517.

Ellis, J.C. 2005.Marine birds on land: a review of plant biomass, species richness, and community composition in seabird colonies. Plant Ecol. 181:227-241. 
Enge, K.M. 2001 The pitfalls of pitfall traps. J. Herptol. 35:467-478.

Epskamp, S., G. Costantini, J. Haslbeck, A.O.J. Cramer, L.J. Waldorp, V.D. Schmittmann and D Borsboom. 2017. qgraph Graph plotting methods, psychometric data visualisations and graphical model estimation. R package version 1.4.4. CRAN.

Fischer, J.H., J. Chambon, I. Debski, J.A. Hiscock, R. Cole, G.A. Taylor and H.U. Wittmer. 2018a. Buffering artificial nest boxes for Procellariiformes breeding in exposed habitats: investigating effects on temperature and humidity. Notornis 65:35-41.

Fischer, J.H., I. Debski, C.M. Miskelly, A.J.D. Tennyson, A. Fromant, J. Tessler, J.A. Hiscock, R. Cole, C.A. Bost, G.A. Taylor and H.U. Wittmer. 2018b. Analyses of phenotypic differentiations between South Georgian Diving Petrel (Pelecanoides georgicus) populations reveal an undescribed and highly-endangered species from New Zealand. PLOS ONE 13(6):e0197766.

Fischer, J.H., I. Debski, G.A. Taylor and H.U. Wittmer. 2017a. Assessing the suitability of non-invasive methods to monitor interspecific interactions and breeding biology of the South Georgian diving petrel (Pelecanoides georgicus). Notornis 64: 13-20.

Fischer, J.H., I. Debski, G.A. Taylor and H.U. Wittmer. 2018c. Nest site selection of South Georgia diving-petrels Pelecanoides georgicus on Codfish Island, New Zealand: implications for conservation management. Bird Conserv. Int. 28:216-227.

Fischer, J.H., F.O. Hjorsvarsdottir, J.A. Hiscock, I. Debski, G.A Taylor GA and H.U. Wittmer. 2017b. Confirmation of the extinction of South Georgian diving petrels (Pelecanoides georgicus) on Enderby Island. Notornis 64:48-51.

Fischer, J.H., H. U. Wittmer, E. Setiawan, S. Jaffe and A.J. Marshall. 2017c. Incipient loss of a rainforest mutualism? J. Threat. Taxa 9:9734-9737.

Fukami, T., D.A. Wardle, P.J. Bellingham, C.P.H. Mulder, D.R. Towns, G.W. Yeates, K.I Bonner, M.S. Durrett, M.N. GrantHoffman and W. M. Williamson. 2006. Above- and belowground impacts of introduced predators in seabird-dominated island ecosystems. Ecol. Lett. 9:1299-1307.

Graham, N.A.J., S.K. Wilson, P. Carr, A.S. Hoey, S. Jennings and M.A. MacNeil. 2018. Seabirds enhance coral reef productivity and functioning in the absence of invasive rats. Nature 559:250253.

Heine, J.C. and T.W. Speir TW. 1989. Ornithogenic soils of the Cape Bird Adelie penguin rookeries, Antarctica. Polar Biol. 10:89100 .

Herbert, S. and T. Bell. 2012. Survey design options for monitoring lizards at Baring Head, East Harbour Regional Park. EcoGecko Consultants, New Plymouth.

Hines, J.E. 2006. PRESENCE - Software to estimate patch occupancy and related parameters. USGS-PWRC. http://www.mbrpwrc.usgs.gov/software/presence.html.

Hitchmough, R., B. Barr, M. Lettink, J. Monks, R. Reardon, M. Tocher, D. van Winkel and J. Rolfe. 2016. Conservation status of New Zealand reptiles, 2015. Department of Conservation, Wellington.

Holdaway, R.N., M.D. Jones and N.R.B Athfield. 2003. Establishment and extinction of a population of South Georgian diving petrel (Pelecanoides georgicus) at Mason Bay, Steward Island, New Zealand, during the late Holocene. J. Roy. Soc. New Zeal. 33: 601-622.

Jewell, T. 2017. Skinks of Southern New Zealand (2 ${ }^{\text {nd }}$ Ed.). Online publication [accessed on 13 February 2018].

Lameris, T.K., J.R. Bennett, L.K. Blight, M. Giessen, M.H. Janssen, J.J.H.J. Schaminee and P. Arcese. 2016. A century of ecosystem change: human and seabird impacts on plant species extirpation and invasion on islands. PeerJ 4:e2208.

Lorrain, A., F. Houlbreque, F. Benzoni, L. Barjon, L. Tremblay-Boyer, C. Menkes, D.P. Gillikin, C. Payri, H. Jourdan, G. Boussarie, A. Verheyden and E. Vidal. 2017. Seabirds supply nitrogen to reefbuilding corals on remote Pacific islets. Sci. Rep. 7:3721.

MacKenzie, D. I., L.L. Bailey and J.D. Nichols. 2004. Investigating species co-occurrence patterns when species are detected imperfectly. J. Anim. Ecol. 73:546-555.

MacKenzie, D.I., J.D. Nichols, J.E. Hines, M.G. Knutson and A.B. Franklin. 2003. Estimating site occupancy, colonization, and local extinction probabilities when a species is detected imperfectly. Ecology 84:2200-2207.

MacKenzie, D.I., J.D. Nichols, G.B. Lachman, S. Droege, J.A. Royle and C.A. Langtimm. 2002. Estimating site occupancy rates when detection probabilities are less than one. Ecology 83:2248-2255.

MacKenzie, D.I., J.D. Nichols, J.A. Royle, K.H. Pollock, L.L. Bailey and J.E. Hines. 2018. Occupancy estimation and modelling Inferring patterns and dynamics of species occurrence. $2^{\text {nd }}$ edition. Elsevier, London.

Markwell, T.J. and C.H. Daugherty. 2002. Invertebrate and lizard abundance is greater on seabird-inhabited islands than on seabird-free islands in the Marlborough Sounds, New Zealand. Ecoscience 9:293-299.

McClelland, P.J. 2002. Eradication of Pacific rats from Whenua Hou Nature Reserve (Codfish Island), Putauhinu and Rarotoka Islands, New Zealand. Turning the tide: eradication of invasive species 27:173-181.

Melzer, S., T. Bell and G.B. Patterson. 2017. Hidden conservation vulnerability within a cryptic species complex: taxonomic revision of the spotted skink (Oligosoma lineoocellatum; Reptilia: Scincidae) from New Zealand. Zootaxa 4300:355-379.

Middleton, A. 2007. Two hundred years on Codfish Island (Whenuahou). Department of Conservation, Invercargill.

Milne, T., C.M. Bull and M.N. Hutchinson. 2003. Use of burrows by the endangered pygmy blue-tongue lizard, Tiliqua adelaidensis (Scincidae). Wildlife Res. 30:523-528.

Miskelly, C.M. and G.A. Taylor. 2004. Establishment of a colony of Common Diving Petrels (Pelecanoides urinatrix) by chick transfers and acoustic attraction. Emu 104:205-211.

Miskelly, C.M., G.A. Taylor, H. Gummer and R. Williams. 2009. Translocations of eight species of burrow-nesting seabirds (genera Pterodroma, Pelecanoides, Pachyptila and Puffinus: Family Procellaridae). Biol. Conserv. 142:1965 - 1980.

Mulder, C.P. and S.N. Keall. 2001. Burrowing seabirds and reptiles: impact on seeds, seedlings and soils in an island forest in New Zealand. Oecologia 127:350-360.

Orwin, K.H., D.A. Wardle, D.R. Towns, M.G. John, P.J. Bellingham, C. Jones, B.M. Fitzgerald, R.G. Parrish and P.O. Lyver. 2016. Burrowing seabird effects on invertebrate communities in soil and litter are dominated by ecosystem engineering rather than nutrient addition. Oecologia 180:217-230.

Otero, X.L., S. de la Peña-Lastra, A. Pérez-Alberti, T.O. Ferreira and M.A. Huerta-Diaz. 2018. Seabird colonies as important drivers in the nitrogen and phosphorus cycles. Nat. Commun. 9:246.

Petren, K. and T.J. Case. 1998. Habitat structure determines competition intensity and invasion success in gecko lizards. $P$. Natl. Acad. Sci. U.S.A. 95:11739-11744.

Phillpot, P. 2000 The skinks of Northern Brother Island: Abundance, habitat use, and species interactions. MSc Thesis, Victoria Univ. of Wellington, Wellington. 
R Development Core Team. 2016. R: A language and environment for statistical computing. Version 3.3.1. R Foundation for Statistical Computing, Vienna.

Richmont, O.M.W., J.E. Hines and S.R. Beissinger. 2010. Twospecies occupancy models: a new parameterization applied to co-occurrence of secretive rails. Ecol. Appl. 20:2036-2046.

Robertson, H.A., K. Baird, J.E. Dowding, G.P. Elliott, R.A. Hitchmough, C.M. Miskelly, N. McArthur, C.F.J. O’Donnell, P.M. Sagar, R.P. Scofield and G.A. Taylor. 2017. Conservation status of New Zealand birds, 2016. Department of Conservation, Wellington.

Roughton, C.M. 2005. Assessment of Methods to Monitor Otago Skink and Grand Skink Populations, New Zealand. Department of Conservation, Wellington.

Seber, G.A.F. 1982. The Estimation of Animal Abundance and Related Parameters, 2nd Edition. Macmillan, New York.

Seddon, P.J., C.J. Griffiths, P.S. Soorae and D.P. Armstrong. 2014. Reversing defaunation: Restoring species in a changing world. Science 345:406-412.

Seddon, P.J., C.M. Roughton, J. Reardon and D.I. MacKenzie. 2011. Dynamics of an endangered New Zealand skink: accounting for incomplete detectability in estimating patch occupancy. New Zeal. J. Ecol. 35:247-253.

Şekercioğlu, Ç., G.C. Daily and P.R. Ehrlich. 2004. Ecosystem consequences of bird declines. P. Natl. Acad. Sci. U.S.A. 101: 18042-18047.

Şekercioğlu, Ç.H. 2006. Increasing awareness of avian ecological function. Trends Ecol. Evol. 21:464-471.

Souter, N.J., C.M. Bull and M.N. Hutchinson. 2004. Adding burrows to enhance a population of the endangered pygmy blue tongue lizard, Tiliqua adelaidensis. Biol. Conserv. 116:403-408.

Taylor, G.A. 2000a. Action Plan for Seabird Conservation in New Zealand. Part A: Threatened Seabirds. Department of Conservation, Wellington.

Taylor, G.A. 2000b. Action Plan for Seabird Conservation in New Zealand. Part B: Non-threatened Seabirds. Department of Conservation, Wellington.

Towns, D.R., D.A. Wardle, C.P.H. Mulder, G.W. Yeates, B.M. Fitzgerald, G.R. Parrish, P.J. Bellingham and K.I. Bonner. 2009. Predation of seabirds by invasive rats: multiple indirect consequences for invertebrate communities. Oikos 118:420-430.

Trainor, S. 2008. Codfish Island South Georgian Diving Petrel: a summary of field observations 2004-2007 and recommenda- tions for future management. Department of Conservation, Invercargill.

Trainor, S. 2009. South Georgian Diving Petrel: a summary of field observations 2007-2009 on Codfish Island. Department of Conservation, Invercargill.

Trewick, S.A. and G.C. Gibb. 2010. Vicars, tramps and assembly of the New Zealand avifauna: a review of molecular phylogenetic evidence. Ibis 152:256-253.

Tylianakis, J.M., E. Laliberté, A. Nielsen and J. Bascompte. 2010. Conservation of species interaction networks. Biol. Conserv. 143:2270-2279.

Valiente-Banuet, A., A.M. Aizen, J.M. Alcántara, J. Arroyo, A. Cocucci, M. Galetti, M.B. García, D. García, J.M. Gómez, P. Jordano, R. Medel, L. Navarro, J.R. Obeso, R. Oviedo, N. Ramírez, P.J. Rey, A. Traveset, M. Verdú and R. Zamora. 2015. Beyond species loss: the extinction of ecological interactions in a changing world. Funct. Ecol. 29:299-307.

Walls, G. 1978. The influence of the tuatara on Fairy Prion breeding on Stephens Island, Cook Strait. New Zeal. J. Ecol. 1:91-98.

Wardle, D.A., B.J. Bellingham, K.I. Boot and C.P.H. Mulder. 2009. Indirect effects of invasive predators on plant litter quality, decomposition and nutrient resorption on seabird-dominated islands. Ecology 90:452-464.

Wickes, C. and B. Rance. 2010. Sealers Beach Vegetation Survey. Department of Conservation, Invercargill.

Wickham, H. 2009. ggplot2: Elegant Graphics for Data Analysis. Springer, New York

Wood, J.R. 2016 Spatial distribution of late Holocene bird bones in the Mason Bay dune system, Stewart Island, New Zealand. $J$. Roy. Soc. New Zeal. 46:103-116.

Wood, J.R. and S. Briden. 2008. South Georgian diving petrel (Pelecanoides georgicus) bones from a Maori midden in Otago Peninsula, New Zealand. Notornis 55:46-47.

Wood, J.R., R.P. Scofield, J. Hamel, C. Lalas and J.M. Wilmshurst. 2017. Bone stable isotopes indicate a high trophic position for New Zealand's extinct South Island adzebill (Aptornis defossor) (Gruiformes: Aptornithidae). New Zeal. J. Ecol. 41:240-244.

Received February 12, 2019 Revised April 15, 2019 Accepted May 3, 2019 